\title{
Indication for differential sorting of the rat v-SNARE splice isoforms VAMP-1a and $\mathbf{- 1 b}$
}

\begin{tabular}{|r|l|}
\hline Journal: & Biochemistry and Cell Biology \\
\hline Manuscript ID & bcb-2016-0184.R2 \\
\hline Manuscript Type: & Article \\
\hline Date Submitted by the Author: & 20 -Feb-2017 \\
\hline Complete List of Authors: & $\begin{array}{l}\text { Rodepeter, Fiona; Universitatsklinikum Giessen und Marburg - Standort } \\
\text { Marburg } \\
\text { Wiegand, Susanne; Universitatsklinikum Giessen und Marburg - Standort } \\
\text { Marburg } \\
\text { Lüers, Hans-Georg; Philipps-Universitat Marburg; Universitatsklinikum } \\
\text { Hamburg-Eppendorf } \\
\text { Bonaterra, Gabriel; Philipps-Universitat Marburg } \\
\text { Lowe, Anson; Stanford University } \\
\text { Bette, Michael; Philipps-Universitat Marburg } \\
\text { Jacob, Ralf; Philipps-Universitat Marburg } \\
\text { Mandic, Robert; Universitatsklinikum Giessen und Marburg - Standort } \\
\text { Marburg, Otolaryngology }\end{array}$ \\
\hline Please Select from this Special & N/A \\
\hline Issues list if applicable: & VAMP, SNARE, sorting, intracellular trafficking, subcellular compartment \\
\hline
\end{tabular}




\section{Indication for differential sorting of the rat v-SNARE splice isoforms}

\section{VAMP-1a and $-1 b$}

Fiona R. Rodepeter, Susanne Wiegand, Hans-Georg Lüers, Gabriel A. Bonaterra, Anson W. Lowe, Michael Bette, Ralf Jacob, Robert Mandic.

\section{Affiliations:}

F. R. Rodepeter, S. Wiegand, R. Mandic. Department of Otorhinolaryngology, Head and Neck Surgery, University Hospital Giessen and Marburg, Campus Marburg, Marburg, Germany.

H.-G. Lüers. Department of Cell Biology, Institute of Anatomy and Cell Biology, Philipps-Universität, Marburg, Germany. New address: Institute of Anatomy and Experimental Morphology, University Hospital Hamburg-Eppendorf, Hamburg, Germany.

G. A. Bonaterra. Department of Medical Cell Biology, Philipps-Universität, Marburg, Germany.

A. W. Lowe. Department of Medicine, Stanford University, Stanford, CA, USA.

M. Bette. Department of Molecular Neuroscience, Institute of Anatomy and Cell Biology, Philipps-Universität, Marburg, Germany.

R. Jacob. Institute of Cell Biology and Cell Pathology, Philipps-Universität, Marburg, Germany.

Corresponding author: Robert Mandic (e-mail: mandic@med.uni-marburg.de) 
Abstract: SNARE (soluble $\underline{\mathbf{N}}$-ethylmaleimide-sensitive factor attachment protein receptor) proteins are essential constituents of the intracellular trafficking machinery. The variable C-terminus in the two rat VAMP-1 splice isoforms VAMP-1a and $-1 b$ potentially acts as a sorting signal since similar changes at the C-terminal end of a human VAMP-1 splice isoform resulted in its sorting to mitochondria. To evaluate differences in the subcellular localization of these two v-SNARE proteins, GFP and RFP tagged VAMP-1a and $-1 \mathrm{~b}$ proteins were expressed in HeLa, COS-7 and MDCK cells and evaluated by conventional confocal as well as total internal reflection fluorescence (TIRF) microscopy. Regions consistent with the endoplasmic reticulum (ER) and Golgi apparatus demonstrated a major overlap of both signals. In the periphery, vesicular structures were observed that expressed mainly one of both isoforms. Within our experimental settings, we could not observe sorting of any of the two isoforms to mitochondria or peroxisomes, whereas both isoforms were found expressed in a minor subset of singular vesicles, which sporadically appear to colocalize with the exocyst marker EXOC3/Sec6. Since vesicular structures were seen that expressed only one of the two splice variants, it is possible that VAMP-1a and VAMP-1b are sorted to distinct cellular compartments which require further characterization.

Keywords: VAMP, SNARE, sorting, intracellular trafficking, subcellular compartment 


\section{Introduction}

Intracellular transport of vesicles and their regulated fusion with target membranes such as the plasma membrane or intracellular compartments is a fundamental process in cell biology (Bennett and Scheller 1993; Rothman and Warren 1994). Socalled SNAREs (soluble $\underline{\mathbf{N}}$-ethylmaleimide-sensitive factor attachment protein receptors) are proteins that participate in constitutive or regulated vesicle docking and fusion events (Jahn et al. 2003; Sollner et al. 1993). VAMPs (vesicle asssociated membrane proteins) as members of this apparatus have initially been characterized as components of synaptic vesicles in Torpedo californica (Trimble et al. 1988) and were independently identified in rat where they were termed synaptobrevins (Baumert et al. 1989). They belong to a small family of membrane proteins (Kutay et al. 1995) that are highly conserved from yeast to mammals (Bennett and Scheller 1993; Gerst et al. 1992) and have been characterized in many species such as yeast, drosophila, rat and human (Archer et al. 1990; Chin et al. 1993; DiAntonio et al. 1993; Elferink et al. 1989; Protopopov et al. 1993; Sudhof et al. 1989). Their involvement and importance for vesicle fusion is confirmed by the observation that specific cleavage of VAMPs by zinc-metalloproteases such as clostridial neurotoxins inhibits regulated membrane fusion (Link et al. 1993; Schiavo et al. 1992; Schiavo et al. 1994; Schiavo et al. 1993; Yamasaki et al. 1994). In a 20 S complex of SNAP25, NSF and VAMP-2, the VAMP protein serves as a receptor that is located on the vesicle membrane and links the vesicle to attachment factors on the target membrane (Sollner et al. 1993). Furthermore, yeast studies involving VAMP homologues revealed a role of VAMP not only in vesicle docking (Broadie et al. 1995; Hunt et al. 1994) but also in targeted vesicle transport (Dascher et al. 1991; Ossig et al. 1991). In these studies, mutational changes in the supposed sorting domain lead to an alternative subcellular localization (Ferro-Novick and Jahn 1994; Gerst 1997; 
Grote et al. 1995). Even earlier it has been proposed that transport pathways between distinct compartments require their own subset of SNARE components (Calakos et al. 1994; Grote et al. 1995; Parlati et al. 2000; Sollner et al. 1993) and that compartmental specificity is encoded in SNARE proteins (McNew et al. 2000). While the highly conserved hydrophilic domain of VAMP located in the cytosol serves as a binding site for syntaxin thereby acting as a fusion mediator (Archer et al. 1990; Elferink et al. 1989), the function of its C-terminus is not completely understood. Since the C-terminal end that is predicted to extend into the vesicle lumen comprises only a few amino acids, no isoform specific antibodies could be generated so far that could distinguish the VAMP-1 isoforms (Elferink et al. 1989; Sudhof et al. 1989). A VAMP-1 isoform, referred to as VAMP-1b, which differs from the original VAMP-1a in its C-terminal sequence was previously characterized in mammals (Mandic et al. 1997). It has been demonstrated that it is generated by alternative RNA splicing, a process that earlier has been described for VAMP homologues in Drosophila melanogaster (Chin et al. 1993). VAMP-1a and -1b show tissue-specific expression levels thereby pointing to a tissue specific function of these isoforms (Mandic et al. 1997). The first evidence that the C-terminus of different VAMP-1 isoforms may encode distinct sorting signals was provided by Isenmann and co-workers (Isenmann et al. 1998). Here the C-terminus was shown to function as a sorting signal in a human VAMP-1 isoform (VAMP-1B), which is different from rat VAMP-1b, since this VAMP-1 isoform was targeted to mitochondria instead of endosomal-like structures and the plasma membrane as observed by the same group. In the present study, we evaluated potential differences between the subcellular localization of the rat VAMP1 isoforms VAMP-1a and $-1 \mathrm{~b}$ by using fluorescence microscopy techniques on GFPand RFP-tagged VAMP-1 proteins in conjunction with immunocytochemistry. 
Furthermore we used total internal reflection fluorescence (TIRF) microscopy to study the localization of VAMP-1a and $-1 b$ in living cells.

\section{Materials and methods}

\section{Generation of VAMP-1 expression vectors}

A vector, containing the entire coding sequence of VAMP-1 was kindly provided by W. Trimble (University of Toronto and Division of Cell Biology, Toronto, Ontario, Canada) and was used as a template for subsequent PCR-based cloning procedures. HindIII and EcoRI restriction sites were introduced into the respective 5' and 3' primers. Since the first 371 nucleotides in both isoforms are identical, the same 5'-primer, containing a Hindlll restriction site (5'TTACAAGCTTCGATGTCTGCTCCAGCTCAGCCACCTGC-3'), was used for amplification of both isoforms. The VAMP-1a and $-1 \mathrm{~b}$ specific C-terminal sequence was included in the respective primers at the 3'-end together with an EcoRI restriction site (VAMP-1a - reverse complement: AGAATTCGATCAAGTAAAAATGTAGATTACAATTA-3'; VAMP-1b - reverse complement: AGAATTCGATCAGCGATACTTACTTACAATTACTACCACGATGATGG-3'). primers were obtained from Invitrogen $\mathrm{GmbH}$ (Karlsruhe, Germany). PCR was carried out with a thermocycler from Biometra (Model T Professional, Göttingen, Germany), with the following settings: $96^{\circ} \mathrm{C} \times 1 \mathrm{~min}, 60^{\circ} \mathrm{C} \times 2 \mathrm{~min}, 72^{\circ} \mathrm{C} \times 3 \mathrm{~min}(40$ cycles) and $72^{\circ} \mathrm{C} \times 15 \mathrm{~min}$. PCR products were run on a $1.2 \%$ agarose gel followed by gel-purification (QIAGEN ${ }^{\circledR}$ Gel Extraction Kit, QIAGEN, Hilden, Germany) according to the manufacturers' instructions. Fluorescence protein encoding vectors (pEGFP-C1, pDsRed-Monomer-C1) were from Clontech Laboratories, Inc. (Mountain View, CA, USA). The purified PCR products and both vectors were double-digested 
with HindIII and EcoRI (New England Biolabs, Ipswitch, MA, USA) and gel purified. Subsequently vectors and products were treated with T4 DNA ligase (New England Biolabs) to generate GFP-VAMP-1a, GFP-VAMP-1b, RFP-VAMP-1a and RFPVAMP-1b encoding expression vectors. Selection was performed after transformation of DH5a competent cells (Life Technologies $\mathrm{GmbH}$, Darmstadt, Germany). Plasmids were purified with the QIAGEN Plasmid Midi kit. All constructs were sequenced by a commercial provider (4BaseLab, Reutlingen, Germany).

\section{Cell culture and transfection}

HeLa, COS-7 and MDCK cells (Gluzman 1981; Scherer et al. 1953; Gaush et al. 1966) were cultured in DMEM (Dulbecco's Modified Eagle Medium) in the presence of $10 \%$ FCS, $1 \%$ L-glutamine, $100 \mathrm{U} / \mathrm{l}$ penicillin and $100 \mu \mathrm{g} / \mathrm{ml}$ streptomycin. Cell culture medium was replaced every three days. Cells were grown on cover slips, placed in 6-well-plates until reaching $90 \%$ confluence followed by transfection with 4 $\mu \mathrm{g}$ of the VAMP-1 encoding GFP/RFP plasmids using Lipofectamine ${ }^{\circledR} 2000$ (Life Technologies $\mathrm{GmbH}$ ).

\section{Antibodies}

Anti-VAMP-1 rabbit polyclonal antibody (ab3346) and GFP mouse monoclonal antibody (ab1218) were purchased from Abcam (Cambridge, UK). Mouse monoclonal antibodies directed against beta-actin (A5316) were purchased from Sigma-Aldrich (Munich, Germany), and DsRed rabbit polyclonal antibody (632496) from Clontech Laboratories, Inc.. The anti-Rab4 (610888) and anti-Rab11 (610657) antibodies were from BD Biosciences (Heidelberg, Germany) and the antiEXOC3/Sec6 antibody (ADI-VAM-SV021, Stressgen®) from Enzo Life Sciences, Inc. (Farmingdale, NY, USA). The anti-mouse Alexa Fluor 647 antibody (A-21235, 
Invitrogen ${ }^{\mathrm{TM}}$ ) was purchased from Thermo Fisher Scientific Inc. (Waltham, MA, USA). All other antibodies were obtained from Santa Cruz Biotechnologies Inc. (Santa Cruz, CA, USA): Anti-TOM20 (sc-17764, mouse monoclonal), donkey anti-mouse IgGRhodamine (sc-2300), goat anti-mouse IgG-horseradish peroxidase (sc-2005), goat anti-rabbit IgG-horseradish-peroxidase (sc-2054).

\section{Western Blot analysis}

Cells were trypsinized and collected in $4 \mathrm{ml}$ DMEM, followed by pelleting at $350 \mathrm{~g}$ for 5 min. After washing the pellet in PBS and centrifugation, the supernatant was discharged. For sample preparation, the pellet was solved in two (pellet) volumes of lysis buffer $(137 \mathrm{mM} \mathrm{NaCl}, 20 \mathrm{mM}$ TrisHCl/pH 7.5, 10\% glycerol, 1\% Nonidet P-40, containing protease and phosphatase inhibitors), followed by incubation for $30 \mathrm{~min}$ at $4^{\circ} \mathrm{C}$. After centrifugation for $15 \mathrm{~min}\left(13,000 \mathrm{rpm}, 4^{\circ} \mathrm{C}\right)$, the supernatant was collected followed by measuring the protein concentration (Bradford 1976). 5-40 $\mu \mathrm{g}$ of protein per lane was separated on a 15\% SDS-Gel (Laemmli 1970). Proteins were subsequently transferred to a nitrocellulose membrane (Towbin et al. 1979). After transfer, membranes were incubated in blocking buffer (TBS, 0.1\% Tween-20, 5\% non-fat dry milk) for 30 min. Primary antibodies (anti-VAMP-1, anti-GFP, anti-DsRed, anti-beta-actin) were incubated over night at $4^{\circ} \mathrm{C}$ in blocking buffer. Subsequently, membranes were washed thrice for $5 \mathrm{~min}$ in blocking buffer, followed by addition of the secondary HRP (horse radish peroxidase)-coupled antibody (1:2000, $1 \mathrm{~h}$ at RT). Membranes were washed thrice as described above followed by addition of ECL (enhanced chemiluminescent) solution (Thermo Fisher Scientific) to each membrane and subsequent exposure to x-ray film (Optimax Typ TR, PROTEC, Obererstenfeld, Germany). 


\section{Fluorescence Microscopy}

For fluorescence microscopy, involving GFP or RFP expressing plasmids only, transfected cells were washed twice for $5 \mathrm{~min}$ in phosphate buffered saline (PBS) $48 \mathrm{~h}$ after of transfection followed by fixation for $5 \mathrm{~min}$ in ice-cold $\left(-20^{\circ} \mathrm{C}\right)$ methanol. Subsequently, cells were washed twice in PBS and once in distilled water followed by covering cells with Mountain Dew Fluorescence Medium (DakoCytomation, Hamburg, Germany). If immunocytochemistry was used in addition, cells were washed thrice in PBS, fixed in precooled $\left(-20^{\circ} \mathrm{C}\right)$ methanol for $5 \mathrm{~min}$, followed by $3 \mathrm{x}$ PBS washing. After 15 min incubation in staining buffer (PBS, 3\%BSA, 0.3\% NP40), primary antibodies (anti-rab4, anti-rab11, anti-EXOC3/Sec6, anti-TOM20) were applied in the same buffer at a dilution of 1:250. After $3 x$ washing, secondary antibodies (anti-mouse, anti-rabbit or anti-goat antibodies, conjugated to Rhodamine (1:500) or Alexa Fluor 647 (1:250) were added for $1 \mathrm{~h}$, followed by a washing step in staining buffer, PBS, $1 \mu \mathrm{g} / \mathrm{ml}$ DAPI (in $\mathrm{H}_{2} \mathrm{O}$ ) for $10 \mathrm{~min}$ and finally in distilled water. Subcellular localization was evaluated by confocal fluorescence microscopy (Axio Imager M2, Carl Zeiss GmbH, Jena, Germany) using the AxioVision Rel. 4.8 software. 48 hours after transfection, cells were evaluated by TIRF microscopy (LEICA DMI 6000 B microscope, LEICA Microsystems GmbH, Wetzlar, Germany). Conventional confocal microscopy: GFP was excited at $488 \mathrm{~nm}\left(\mathrm{AR}^{+}\right.$-laser) and emission was monitored at 500-520 nm. RFP and Rhodamine were excited with a HeNe-laser at $543 \mathrm{~nm}$ and emission was detected at 560-620 nm. To visualize Alexa 647, the specimens were exposed to $633 \mathrm{~nm}$ (excitation) light (HeNe-laser) and emission was detected at 645-675 nm. TIRF microscopy: $488 \mathrm{~nm}(300 \mathrm{~mW})$ and 532 $\mathrm{nm}(500 \mathrm{~mW})$ solid-state lasers were used for excitation of GFP and RFP, respectively. The corresponding filter cube settings are shown in supplementary Fig. 1. The penetration depth of the evanescent light was $110 \mathrm{~nm}$. The total length of the 
series shown in Figures 3 and 4 was $5 \mathrm{~min}$ and $17.141 \mathrm{~s}$. The total number of exposures in this series was 182 corresponding to 91 frames, each frame comprising of images from 2 channels which were recorded successively (GFP: exposure time $=277 \mathrm{~ms}$, gain=2.7 and RFP: exposure time=932ms, gain=5.0). Fluorescent beads were used for technical validation of the TIRF microscopical settings (see supplementary Fig. 1). Subsequent image analysis was performed with the LAS AF Version 2.6.0 software (LEICA Microsystems $\mathrm{GmbH}$ ).

\section{Results}

Expression of GFP- and RFP-tagged VAMP-1a and -1b proteins in COS-7 and HeLa cells was evaluated by Western blot analysis and immunocytochemistry (Fig. 1). All constructs expressed proteins of predicted size exhibiting immunoreactivity to antibodies directed against GFP, RFP as well as VAMP-1 (Fig. 1A). Transfection of HeLa cells with the same constructs revealed a strong and distinct intracellularvesicular and plasma membrane fluorescence for all VAMP-1 fusion proteins (Fig. 1B). To evaluate the level of colocalization between the different VAMP-1 isoforms, GFP-VAMP-1a and RFP-VAMP-1b or GFP-VAMP-1b and RFP-VAMP-1a encoding plasmids were cotransfected into HeLa cells with subsequent analysis by fluorescence microscopy (Fig. 2A). As expected for VAMP-1 proteins, a major overlap of green and red fluorescence was seen in regions consistent with the endoplasmic reticulum (ER) and Golgi apparatus. In peripheral regions of the cell, vesicular structures could be seen that carried only one of the two tested isoforms, being visible in only one of the channels (GFP or RFP) (Fig. 2A, arrows). After cotransfecting same but differently tagged VAMP-1 isoforms (GFP-VAMP-1a and RFP-VAMP-1a or GFP-VAMP-1b and RFP-VAMP-1b), an extensive overlap of the fluorescence signals could be seen as expected (Fig. 2B). Similarly as in Fig. 2A, 
vesicular structures were observed that appeared to carry only one of the fusion proteins, either GFP- or RFP-VAMP-1. However, when looking at the single fluorescence channels (GFP and RFP) in Fig. 2B, the differently tagged identical VAMP-1 proteins are found to reside in the same vesicular structure (arrow), which was not obvious when looking only at the merged image. Therefore, different $\mathrm{N}$ terminal GFP- and RFP-tags do not appear to have a major influence on VAMP-1 sorting. However, due to the limitations of studies using fixed cells no final conclusion about the extent of colocalization of both VAMP-1 isoforms was possible. To overcome these limitations, total internal reflection fluorescence (TIRF) microscopy was deployed to investigate vesicle movement in living COS-7 cells, cotransfected with both VAMP-1 isoforms. Next to regions of colocalization, distinct red vesicles could be observed carrying mainly the VAMP-1b isoform, thereby pointing to the presence of a vesicle population to which VAMP-1b preferentially sorts (Fig. 3A, see also supplemental file S1_movie). Tracking several of the vesicles (1-6) over time reveals major differences in the extent of vesicle motility (Fig. 3B). In addition, vesicles could be observed coming into close vicinity to each other without obvious fusion (Fig. 4A, see supplemental file S2_movie), whereas other vesicles contact each other followed by subsequent fusion (Fig. 4B, see supplemental file S3_movie). Interestingly, not only vesicular but also tubular structures, positive for both isoforms, could be seen during TIRF microscopy (Fig. 3A and 4) possibly representing nearmembrane endosomal structures.

\section{VAMP-1a and VAMP-1b do not colocalize with mitochondria.}

No colocalization of VAMP-1a and $-1 b$ was seen with the mitochondrial marker TOM20 (Fig. 5A and B), largely excluding sorting of any of the two isoforms to mitochondria. This observation is in line with observations made for the human 
isoform of rat VAMP-1a as reported by Isenmann and colleagues (Isenmann et al, 1998).

\section{Resemblance of the C-terminus of VAMP-1b with peroxisomal targeting signal 1 (PTS-1)}

Since the C-terminal sequence -SKYR as found in VAMP-1b shows a striking similarity to peroxisomal targeting signal-1 (PTS-1) -SKL, we were interested in the question if -SKYR could also act as a PTS. Addition of the known PTS1 to the Cterminus of GFP, results in sorting of the GFP-fusion protein to peroxisomes (Fig. 6A, upper image), However, addition of the similar C-terminal sequence present in VAMP-1b (-SKYR) to GFP did not result in peroxisomal targeting of the protein but rather exhibited a diffuse cyto- and nucleoplasmic distribution typically seen for wild type GFP (Fig. 6A, lower image). Since membrane association of the VAMP-1 protein could be a prerequisite for proper sorting, RFP plasmids encoding full length VAMP-1 proteins were cotransfected with the GFP-SKL encoding plasmid. No colocalization of any of the two VAMP-1 splice isoforms could be seen with the peroxisomal marker protein GFP-SKL, making it unlikely that the C-terminal sequence -SKYR in VAMP1b serves as a peroxisomal sorting signal (Fig. 6B).

\section{Co-staining of VAMP-1a and -1b with markers of the secretory pathway.}

To evaluate, if VAMP-1a and $-1 \mathrm{~b}$ show a compartment-specific preference for sorting, we performed co-staining of cells transfected with one of the VAMP-1 isoforms and markers of the endocytic (rab4 and rab11) and exocyst (EXOC3/Sec6) compartments. No obvious major co-localization of the VAMP-1 isoforms with rab4 (supplementary Fig. 2) or rab11 (supplementary Fig. 3) was noted in our experimental settings. When co-staining with EXOC3/Sec6 (supplementary Fig. 4), 
there mainly was no overlap (white arrows) except for single minor regions pointing to possible co-localization (supplementary Fig. 4, asterisks). Similarly, preliminary studies with markers of the lysosomal (LAMP-3), early endosomal (EEA1) and autophagosomal (LC3 $\beta$ ) compartments could not exclude a minor co-localization of both VAMP-1 isoforms with these cellular regions (data not shown).

Furthermore, to evaluate if inhibition of membrane transport and subsequent release (Matlin and Simons 1983) differentially affected VAMP-1a and $-1 \mathrm{~b}$, we incubated MDCK cells, co-expressing GFP-VAMP-1a and RFP-VAMP-1b, for $5 \mathrm{~h}$ at $20^{\circ} \mathrm{C}$ in the presence of $100 \mu \mathrm{M}$ cycloheximide to inhibit de novo protein synthesis. Since both VAMP-1 isoforms are expected to accumulate in the Golgi, one could expect that after releasing the block (incubation at $37^{\circ} \mathrm{C}$ ) VAMP-1a and $-1 \mathrm{~b}$ would possibly more clearly show sorting into different compartments than when observed during regular culture at steady state conditions. One hour after raising the incubation temperature to $37^{\circ} \mathrm{C}$, which is known to be sufficient for releasing the membrane block, we could not see a dramatic change in localization that would point to a major effect on VAMP1 sorting (supplementary Fig. 5). However, since these are only preliminary observations, less pronounced subtle effects on sorting cannot be judged within the scope of these experimental settings.

\section{Discussion}

The potential role of the new C-terminal sequence -SKYR found in the rat splice isoform VAMP-1b could not be unraveled yet. Since the variable C-terminus in VAMP-1 was implicated in protein sorting (Isenmann et al. 1998), the present study used fluorescence microscopy-based techniques to evaluate differences in the subcellular distribution of the rat VAMP-1b isoform in comparison to the initially described isoform VAMP-1a. 


\section{The C-terminus of VAMP-1 as a possible sorting signal}

Isenmann and colleagues described a human VAMP-1 splice variant (Isenmann et al. 1998) which similarly to the reported rat VAMP-1 splice variant (Mandic et al. 1997) differs from the initially reported VAMP-1 protein (Trimble et al. 1988) at its short C-terminal end that is predicted to extend into the vesicle lumen. The mechanism of alternative subcellular targeting by generating isoforms with a differing C-terminus was reported earlier for Syntaxin 2 (Quinones et al. 1999). Interestingly, Isenmann and colleagues could demonstrate that the very C-terminal sequence RRD of their newly discovered isoform VAMP-1B serves as a sorting signal for VAMP-1B to mitochondria. Similarly, mitochondrial sorting of cytochrome b5 is mediated by a C-terminal hydrophobic motif flanked by basic amino acids (De Silvestris et al. 1995). Using fluorescence microscopy, we could rule out a significant targeting of any of the two rat VAMP-1 isoforms to mitochondria.

\section{Similarity of the C-terminal sequence in VAMP-1b with the sorting signal of peroxisomal proteins}

Peroxisomal proteins carry signals that ensure their proper targeting to peroxisomes. One of these signals -SKL (peroxisomal targeting signal 1, PTS1), is located at the C-terminus of peroxisomal proteins (Subramani 1998) and exhibits a striking similarity with the C-terminal sequence -SKYR found in VAMP-1b. Addition of the C-terminal sequence -SKL to a protein like GFP is sufficient for peroxisomal targeting (Monosov et al. 1996). One of the differences between these two sequences however is, that peroxisomal matrix proteins carrying the PTS1 do not need to be membrane attached to be targeted to peroxisomes. In contrast, VAMP-1b proteins are membrane associated and carry the C-terminal sequence -SKYR, which 
is expected to be directed to the vesicle lumen (Elferink et al. 1989; Sudhof et al. 1989). In our studies, neither GFP-SKYR nor full length VAMP-1b could sort to peroxisomes as visible after cotransfection with the peroxisomal marker GFP-SKL. In a similar manner, peroxisomal proteins which are membrane bound are primarily inserted into membranes of the ER before reaching their target organelle, as shown for Pex15p (Elgersma et al. 1997) or peroxisomal APX (Mullen and Trelease 2000). Although sorting of VAMP-1b to peroxisomes appears unlikely, the similarity of both sequences supports the notion that -SKYR could represent a protein sorting signal. Furthermore, -SKYR may yet turn out to be a PTS but under conditions that have yet to be identified.

\section{Other compartments and vesicle fusion.}

According to the SNARE-hypothesis, for membrane fusion to proceed, each membrane requires a transmembrane domain of a SNARE protein, defining the vSNARE containing membrane as the donor and the t-SNARE containing membrane as the acceptor compartment (Bock et al. 2001; Fasshauer et al. 1998). In early and late endosomes, homotypic fusion events are a common observation (Antonin et al. 2000). Vesicle contact can result in complete fusion but can also proceed without final fusion exhibiting so-called "kissing" or "kiss and run" phenotypes characterized by temporary fusion events and exchange of vesicle content with subsequent separation of the vesicles lacking a final complete fusion step (Luzio et al. 2009). An example for the regulation of an intracellular fusion event by exchange of a certain VAMP isoform for another was given by Pryor and colleagues (Pryor et al. 2004), who demonstrated how the exchange of VAMP-8 for VAMP-7 in a complex together with Vti1b/Syntaxin-8 could mediate a switch from heterotypic fusion of late endosomal and lysosomal vesicles to homotypic fusion between late endosomes. In 
our studies, we observed vesicles containing both VAMP-1 isoforms on same vesicles that were capable of fusing with each other. At the same time, there were single vesicles carrying only one of both VAMP-1 isoforms. Although a function of VAMP-1 in this context has not been described to date, such a role appears possible since other isoforms as VAMP-7 and VAMP-8 were allocated to lysosomal membranes and even to the phagosomal compartment (Advani et al. 1999; Fasshauer et al. 1999; Furuta et al. 2010). It seems conceivable that in vivo, the subcellular localization of proteins could be crucial for the formation of SNARE complexes, mediated by regulatory components as tethering factors for example (Parlati et al. 2000). Since only one of the two VAMP-1 splice isoforms dominates in a single tissue (Mandic, et al., 1997), it is possible that next to cellular functions which both isoforms have in common, thereby substituting for each other, there also is an isoform specific function that could be required in a specific tissue, e.g. VAMP-1a in neural and VAMP-1b in non-neural tissues (Mandic, et al., 1997).

\section{Implications of VAMP-1 and its splice isoforms in disease}

In a 2007 study, the authors could relate a nonsense mutation in the VAMP-1 gene to a so-called lethal wasting mutant in the mouse, which is characterized by progressive immobilization and death approximately 2 weeks after birth without showing histopathological cerebral changes (Nystuen et al. 2007). The functional role of VAMP-1 is assumed to be related to calcium dependent transmission within the neuromuscular junction (Liu et al. 2011). Furthermore, expression levels of VAMP-1 were found to be associated with diverse neurological disorders and reactive pathological conditions such as hypoxia. For instance, generalized hypoxia in the brain tissue results in elevated VAMP-1 expression levels whereas another SNARE protein, Syntaxin 1, is suppressed under these conditions (Fei et al. 2007). In a study 
on Alzheimer patients, VAMP-1 was the only tested SNARE protein that was found to be down regulated in all of the investigated brain regions, whereas the t-SNAREs SNAP-25 and syntaxin exhibited normal expression levels (Sze et al. 2000). VAMP-1 appears reduced in the superior temporal gyrus of schizophrenia patients, which is required for speech recognition (Sokolov et al. 2000). Next to motoneurons, VAMP-1 is also expressed in sensory neurons where it is involved in CGRP (calcitonin-generelated-peptide) secretion that plays a role in migraine related vasodilation and can be inhibited by botulinum toxin (Meng et al. 2007). All of these reports refer to the role of the initially discovered VAMP-1 isoform (murine VAMP-1a or human VAMP-1A). Interestingly, in a 2012 study by Bourassa et al., defective mRNA splicing of the VAMP-1 gene was implicated as an underlying cause for hereditary spastic ataxia (HSA) 1 (Bourassa et al. 2012). In this study, the authors identified a mutation at the splicing donor site of exon 4 in the VAMP-1 gene to be responsible for the lack of VAMP-1a transcripts in the brain, which is the dominant VAMP-1 isoform in neural tissues. Instead, transcripts corresponding to VAMP-1b (-1D in humans) were generated, which the authors interpreted as a loss of-function mutation of the VAMP1 gene. Lack of VAMP-1A in the brain stem and cerebellum (Elferink et al. 1989; Trimble et al. 1990) could therefore explain the classic symptoms of the disease, which not only include movement disorders of the lower extremities but also such of the eyes and tongue. However, alternative expression of a VAMP-1b (-1D) like isoform in the central nervous system of patients with spastic ataxia could not be excluded. In this case, one could hypothesize that VAMP-1b (-1D) proteins do not fully substitute for VAMP-1a $(-1 \mathrm{~A})$, which supports a tissue specific function of both isoforms and could also be associated with the altered cellular function because of differential subcellular sorting of the isoforms. 
In the present study we could further narrow down differences in the subcellular localization of both VAMP-1 isoforms. However, more studies are required to further look into the functional role of the very C-terminus in VAMP-1 and its possible implication in VAMP-1 protein sorting.

\section{Acknowledgments}

The authors thank R. Peldszus and G. Sadowski (Department of Otorhinolaryngology, Head and Neck Surgery, University Hospital Marburg, Marburg, Germany) for excellent technical support. We thank Dr. S. Veitinger (Institut für Zytobiologie und Zytopathologie, Philipps-Universität Marburg, Germany) for support during TIRF microscopy. The work was in part supported by the Alfred und Ursula Kulemann Stiftung. The data presented in this manuscript is part of the thesis by $F$. R. Rodepeter.

Fig. 1. Expression of GFP- and RFP tagged VAMP-1a and $-1 \mathrm{~b}$ proteins in COS-7 and HeLa cells. GFP- and RFP-VAMP-1 constructs were generated as described in the material and methods section. (A) Expression of the different constructs was evaluated by Western blot analysis of lysates derived from COS-7 cells transfected with the indicated constructs. Single bands could be observed after deploying antibodies directed against GFP or RFP (upper and middle panel in A). Specific bands, corresponding to the size of the GFP and RFP fusion proteins, were observed when using a VAMP-1 specific antibody (lower panel in A). Here an additional smaller sized band $\left({ }^{*}\right)$ was observed that is not seen on the GFP and RFP blots and likely represents a cleavage product. (B) Confocal microscopy images of methanol-fixed HeLa cells transfected with the indicated constructs reveals a vesicular cytoplasmic fluorescence pattern as well as plasma membrane localization of all four fusion 
proteins. Abbreviations: U=untransfected, V1=VAMP-1, G=GFP, Ga=GFP-VAMP $-1 a$, $\mathrm{Gb}=\mathrm{GFP}-\mathrm{VAMP} 1 \mathrm{~b}, \mathrm{Ra}=\mathrm{RFP}-\mathrm{VAMP}-1 \mathrm{a}, \mathrm{Rb}=\mathrm{RFP}-\mathrm{VAMP}-1 \mathrm{~b}$.

Fig. 2. Indications for differential sorting of VAMP-1a and $-1 b$ in HeLa cells. HeLa cells were transfected with the indicated constructs and fixed in methanol as described in the materials and methods section. (A) Coexpression of GFP- and RFPtagged VAMP-1a and $-1 \mathrm{~b}$ isoforms reveals major regions of overlap, consistent with the expected colocalization of both isoforms in the ER and Golgi. However, in more peripheral regions of the cell, vesicular structures are seen that appear to carry only one of the isoforms (Merge), which becomes more obvious, when comparing the single green (GFP) and red (RFP) channels showing a lack of the respective structure seen in the merged image in one of the single channels (arrows in GFPV1a/RFP-V1b and GFP-V1b/RFP-V1a). (B) After control cotransfections of same VAMP-1 isoforms (GFP-V1a/RFP-V1a and GFP-V1b/RFP-V1b), vesicular structures showing only red or green fluorescence in the merged images can be observed too. However, when comparing the single channels, the same structure can also be found positive for the differentially tagged same VAMP-1 isoform with a weaker signal (arrows), implying that same VAMP-1 isoforms are sorted to the same compartment independently of their N-terminal (GFP or RFP) tag. Confocal microscopy images of methanol-fixed HeLa cells.

Fig. 3. Evidence for single vesicle populations carrying predominantly one VAMP-1 isoform. (A) Deployment of total internal reflection fluorescence (TIRF) microscopy on vital COS-7 cells cotransfected with GFP-VAMP-1a (GFP-V1a) and RFP-VAMP-1b (RFP-V1b) reveals vesicles that mainly contain one VAMP-1 isoform (red vesicles 16). The intense signal seen in the center of the cell (asterisk) could represent a near 
plasma membrane accumulation of GFP/RFP-rich structures or regions of epifluorescence rather than TIRF. (B) The extent of vesicle movement varies between different vesicles within the observed time frame. Some of the vesicles (1 and 5) remain rather stationary whereas others exhibit a marked movement appearing to meet in distinct areas (2-4 and 6).

Fig. 4. Vesicle interaction depicted by TIRF microscopy. (A) Vesicle contact without fusion. Shown is a detail from the same experiment as in Fig. 3 (orange rectangle labeled A in Fig. 3A). Depicted are two vesicles (1 and 2), each carrying mainly one of the two VAMP-1 isoforms, that come into close vicinity and appear to contact each other. No vesicle fusion can be observed. (B) Evidence for homotypic fusion events of vesicles carrying both VAMP-1 isoforms (monitored region corresponds to white rectangle labeled $\mathrm{B}$ in Fig. 3A). TIRF microscopy reveals vesicles carrying both VAMP-1 isoforms (1 and 2) that fuse with each other after coming into close vicinity, resulting in the generation of a larger-sized single vesicle $(1+2)$. RFP-V1b=RFPVAMP-1b, GFP-V1a=GFP-VAMP-1a.

Fig. 5. VAMP-1a and $-1 b$ are not localizing to mitochondria. (A) No colocalization is seen between GFP-VAMP-1a or $-1 b$ (GFP-V1a or $-\mathrm{V} 1 \mathrm{~b})$ and the mitochondrial marker protein TOM20. (B) Detail, showing the lack of colocalization of both VAMP-1 splice isoforms and mitochondria. Confocal microscopy images of methanol-fixed HeLa cells. Arrows in (A) and (B) point to mitochondria (red) and VAMP-1 (green)

Fig. 6. VAMP-1a and $-1 \mathrm{~b}$ do not sort to peroxisomes. (A) Attaching the C-terminal peroxisome targeting signal 1 (PTS1) -SKL to GFP results in sorting of the GFP-SKL protein to peroxisomes in $\mathrm{CHO}$ cells (Monosov et al. 1996) (upper image, typical 
punctate fluorescence pattern), whereas attachment of the similar C-terminal sequence -SKYR that is found in VAMP-1b did not result in peroxisomal targeting (lower image, diffuse cyto- and nucleoplasmic fluorescence pattern). (B) Similarly, no colocalization was seen between RFP-VAMP-1a (RFP-V1a) or RFP-VAMP-1b (RFPV1b) respectively and the peroxisome marker GFP-SKL in HeLa cells. Confocal microscopy images of methanol-fixed $\mathrm{CHO}$ and HeLa cells respectively.

\section{Supplementary Figure 1}

Comparison of TIRF and epifluorescence using fluorescent beads (Flow Check Pro Fluorospheres, $10 \mu \mathrm{m}$, Beckman Coulter). Shown are the wavelengths $(\mathrm{nm})$ used for excitation (Ex), emission (Em) and by the dichroic (DC) filter. Note the differences between evanescent light induced fluorescence (TIRF) and epifluorescence.

\section{Supplementary Figure 2}

No major colocalisation (white arrows) of the early and sorting endosome marker rab4 with the VAMP-1 splice isoforms VAMP-1a and $-1 b$ is seen in methanol-fixed MDCK cells. Confocal microscopy images.

\section{Supplementary Figure 3}

No major colocalisation (white arrows) of the recycling endosome marker rab11 with the VAMP-1 splice isoforms VAMP-1a and $-1 \mathrm{~b}$ is seen in methanol-fixed MDCK cells. Confocal microscopy images.

\section{Supplementary Figure 4}

Possible colocalization of the VAMP-1 splice isoforms with EXOC3/Sec6 positive vesicles. Most of the EXOC3/Sec6 positive vesicles do not show any colocalization 
with the two VAMP-1 isoforms (white arrows). However, sporadically one can observe regions of potential overlap (yellow signal, asterisks). Confocal microscopy images of methanol-fixed MDCK cells.

\section{Supplementary Figure 5}

Inhibition and subsequent release of membrane transport does not seem to differently affect VAMP-1a and VAMP-1b distribution in MDCK cells. VAMP-1 transfected MDCK cells were grown under standard culture conditions (DMEM, 10\% FCS, $37^{\circ} \mathrm{C}, 5 \% \mathrm{CO}_{2}$ ) and were then shifted to $20^{\circ} \mathrm{C}$ (blocking membrane transport) in the presence of $100 \mu \mathrm{M}$ cycloheximide $(\mathrm{CHX})$ (blocking new protein synthesis=pulse) for $5 \mathrm{~h}$. Subsequently cells were shifted to $37^{\circ} \mathrm{C}$ to allow for membrane transport to proceed (Matlin and Simons 1983). No major differences can be seen when comparing the colocalization of untreated cells $\left(37^{\circ} \mathrm{C}\right.$, no $\left.\mathrm{CHX}\right)$ with cells $1 \mathrm{~h}$ after release of the membrane transport block $\left(\mathrm{t}=60 \mathrm{~min} @ 37^{\circ} \mathrm{C}+100 \mu \mathrm{g} / \mathrm{ml} \mathrm{CHX}\right.$ ). Confocal microscopy of methanol-fixed MDCK cells.

\section{References}

Advani, R.J., Yang, B., Prekeris, R., Lee, K.C., Klumperman, J., and Scheller, R.H. 1999. VAMP-7 mediates vesicular transport from endosomes to lysosomes. J.Cell Biol. 146(4): 765-776.

Antonin, W., Holroyd, C., Tikkanen, R., Honing, S., and Jahn, R. 2000. The RSNARE endobrevin/VAMP-8 mediates homotypic fusion of early endosomes and late endosomes. Mol.Biol.Cell 11(10): 3289-3298.

Archer, B.T., III, Ozcelik, T., Jahn, R., Francke, U., and Sudhof, T.C. 1990. Structures and chromosomal localizations of two human genes encoding synaptobrevins 1 and 2. J.Biol.Chem. 265(28): 17267-17273.

Baumert, M., Maycox, P.R., Navone, F., De, C.P., and Jahn, R. 1989. Synaptobrevin: an integral membrane protein of 18,000 daltons present in small synaptic vesicles of rat brain. EMBO J. 8(2): 379-384.

Bennett, M.K., and Scheller, R.H. 1993. The molecular machinery for secretion is conserved from yeast to neurons. Proc.Natl.Acad.Sci.U.S.A 90(7): 2559-2563.

Bock, J.B., Matern, H.T., Peden, A.A., and Scheller, R.H. 2001. A genomic perspective on membrane compartment organization. Nature 409(6822): 839-841. 
Bourassa, C.V., Meijer, I.A., Merner, N.D., Grewal, K.K., Stefanelli, M.G., Hodgkinson, K., Ives, E.J., Pryse-Phillips, W., Jog, M., Boycott, K., Grimes, D.A., Goobie, S., Leckey, R., Dion, P.A., and Rouleau, G.A. 2012. VAMP1 mutation causes dominant hereditary spastic ataxia in Newfoundland families. Am.J.Hum.Genet. 91(3): 548-552.

Bradford, M.M. 1976. A rapid and sensitive method for the quantitation of microgram quantities of protein utilizing the principle of protein-dye binding. Anal.Biochem. 72: 248-254.

Broadie, K., Prokop, A., Bellen, H.J., O'Kane, C.J., Schulze, K.L., and Sweeney, S.T. 1995. Syntaxin and synaptobrevin function downstream of vesicle docking in Drosophila. Neuron 15(3): 663-673.

Calakos, N., Bennett, M.K., Peterson, K.E., and Scheller, R.H. 1994. Protein-protein interactions contributing to the specificity of intracellular vesicular trafficking. Science 263(5150): 1146-1149.

Chin, A.C., Burgess, R.W., Wong, B.R., Schwarz, T.L., and Scheller, R.H. 1993. Differential expression of transcripts from syb, a Drosophila melanogaster gene encoding VAMP (synaptobrevin) that is abundant in non-neuronal cells. Gene 131(2): 175-181.

Dascher, C., Ossig, R., Gallwitz, D., and Schmitt, H.D. 1991. Identification and structure of four yeast genes (SLY) that are able to suppress the functional loss of YPT1, a member of the RAS superfamily. Molecular and cellular biology 11(2): 872885.

De Silvestris, M., D'Arrigo, A., and Borgese, N. 1995. The targeting information of the mitochondrial outer membrane isoform of cytochrome b5 is contained within the carboxyl-terminal region. FEBS letters 370(1-2): 69-74.

DiAntonio, A., Burgess, R.W., Chin, A.C., Deitcher, D.L., Scheller, R.H., and Schwarz, T.L. 1993. Identification and characterization of Drosophila genes for synaptic vesicle proteins. J.Neurosci. 13(11): 4924-4935.

Elferink, L.A., Trimble, W.S., and Scheller, R.H. 1989. Two vesicle-associated membrane protein genes are differentially expressed in the rat central nervous system. J.Biol.Chem. 264(19): 11061-11064.

Elgersma, Y., Kwast, L., van den, B.M., Snyder, W.B., Distel, B., Subramani, S., and Tabak, H.F. 1997. Overexpression of Pex15p, a phosphorylated peroxisomal integral membrane protein required for peroxisome assembly in S.cerevisiae, causes proliferation of the endoplasmic reticulum membrane. EMBO J. 16(24): 7326-7341.

Fasshauer, D., Antonin, W., Margittai, M., Pabst, S., and Jahn, R. 1999. Mixed and non-cognate SNARE complexes. Characterization of assembly and biophysical properties. J.Biol.Chem. 274(22): 15440-15446.

Fasshauer, D., Sutton, R.B., Brunger, A.T., and Jahn, R. 1998. Conserved structural features of the synaptic fusion complex: SNARE proteins reclassified as Q- and RSNAREs. Proc.Natl.Acad.Sci.U.S.A 95(26): 15781-15786.

Fei, G., Guo, C., Sun, H.S., and Feng, Z.P. 2007. Chronic hypoxia stress-induced differential modulation of heat-shock protein 70 and presynaptic proteins. J.Neurochem. 100(1): 50-61.

Ferro-Novick, S., and Jahn, R. 1994. Vesicle fusion from yeast to man. Nature 370(6486): 191-193.

Furuta, N., Fujita, N., Noda, T., Yoshimori, T., and Amano, A. 2010. Combinational soluble N-ethylmaleimide-sensitive factor attachment protein receptor proteins VAMP8 and Vti1b mediate fusion of antimicrobial and canonical autophagosomes with lysosomes. Mol.Biol.Cell 21(6): 1001-1010. 
Gaush, R.C., Walter, W.L., and Smith F. 1966. Characterization of an established line of canine kidney cells (MDCK). Proc. Soc. Exp. Biol. Med. 122: 931-935.

Gerst, J.E. 1997. Conserved alpha-helical segments on yeast homologs of the synaptobrevin/VAMP family of v-SNAREs mediate exocytic function. J.Biol.Chem. 272(26): 16591-16598.

Gerst, J.E., Rodgers, L., Riggs, M., and Wigler, M. 1992. SNC1, a yeast homolog of the synaptic vesicle-associated membrane protein/synaptobrevin gene family: genetic interactions with the RAS and CAP genes. Proc.Natl.Acad.Sci.U.S.A 89(10): 4338-4342.

Gluzman, Y. 1981. SV40-transformed simian cells support the replication of early SV40 mutants. Cell 23(1): 175-182.

Grote, E., Hao, J.C., Bennett, M.K., and Kelly, R.B. 1995. A targeting signal in VAMP regulating transport to synaptic vesicles. Cell 81(4): 581-589.

Hunt, J.M., Bommert, K., Charlton, M.P., Kistner, A., Habermann, E., Augustine, G.J., and Betz, H. 1994. A post-docking role for synaptobrevin in synaptic vesicle fusion. Neuron 12(6): 1269-1279.

Isenmann, S., Khew-Goodall, Y., Gamble, J., Vadas, M., and Wattenberg, B.W. 1998. A splice-isoform of vesicle-associated membrane protein-1 (VAMP-1) contains a mitochondrial targeting signal. Mol.Biol.Cell 9(7): 1649-1660.

Jahn, R., Lang, T., and Sudhof, T.C. 2003. Membrane fusion. Cell 112(4): 519-533.

Kutay, U., hnert-Hilger, G., Hartmann, E., Wiedenmann, B., and Rapoport, T.A. 1995. Transport route for synaptobrevin via a novel pathway of insertion into the endoplasmic reticulum membrane. EMBO J. 14(2): 217-223.

Laemmli, U.K. 1970. Cleavage of structural proteins during the assembly of the head of bacteriophage T4. Nature 227(5259): 680-685.

Link, E., McMahon, H., Fischer von, M.G., Yamasaki, S., Niemann, H., Sudhof, T.C., and Jahn, R. 1993. Cleavage of cellubrevin by tetanus toxin does not affect fusion of early endosomes. J.Biol.Chem. 268(25): 18423-18426.

Liu, Y., Sugiura, Y., and Lin, W. 2011. The role of synaptobrevin1/VAMP1 in Ca2+triggered neurotransmitter release at the mouse neuromuscular junction. J.Physiol 589(Pt 7): 1603-1618.

Luzio, J.P., Parkinson, M.D., Gray, S.R., and Bright, N.A. 2009. The delivery of endocytosed cargo to lysosomes. Biochem.Soc.Trans. 37(Pt 5): 1019-1021.

Mandic, R., Trimble, W.S., and Lowe, A.W. 1997. Tissue-specific alternative RNA splicing of rat vesicle-associated membrane protein-1 (VAMP-1). Gene 199(1-2): 173-179.

Matlin, K.S., and Simons K. 1983. Reduced temperature prevents transfer of a membrane glycoprotein to the cell surface but does not prevent terminal glycosylation. Cell 34: 233-243.

McNew, J.A., Parlati, F., Fukuda, R., Johnston, R.J., Paz, K., Paumet, F., Sollner, T.H., and Rothman, J.E. 2000. Compartmental specificity of cellular membrane fusion encoded in SNARE proteins. Nature 407(6801): 153-159.

Meng, J., Wang, J., Lawrence, G., and Dolly, J.O. 2007. Synaptobrevin I mediates exocytosis of CGRP from sensory neurons and inhibition by botulinum toxins reflects their anti-nociceptive potential. J.Cell Sci. 120(Pt 16): 2864-2874.

Monosov, E.Z., Wenzel, T.J., Luers, G.H., Heyman, J.A., and Subramani, S. 1996. Labeling of peroxisomes with green fluorescent protein in living $P$. pastoris cells. J.Histochem.Cytochem. 44(6): 581-589.

Mullen, R.T., and Trelease, R.N. 2000. The sorting signals for peroxisomal membrane-bound ascorbate peroxidase are within its C-terminal tail. J.Biol.Chem. 275(21): 16337-16344. 
Nystuen, A.M., Schwendinger, J.K., Sachs, A.J., Yang, A.W., and Haider, N.B. 2007. A null mutation in VAMP1/synaptobrevin is associated with neurological defects and prewean mortality in the lethal-wasting mouse mutant. Neurogenetics. 8(1): 1-10.

Ossig, R., Dascher, C., Trepte, H.H., Schmitt, H.D., and Gallwitz, D. 1991. The yeast SLY gene products, suppressors of defects in the essential GTP-binding Ypt1 protein, may act in endoplasmic reticulum-to-Golgi transport. Molecular and cellular biology 11(6): 2980-2993.

Parlati, F., McNew, J.A., Fukuda, R., Miller, R., Sollner, T.H., and Rothman, J.E. 2000. Topological restriction of SNARE-dependent membrane fusion. Nature 407(6801): 194-198.

Protopopov, V., Govindan, B., Novick, P., and Gerst, J.E. 1993. Homologs of the synaptobrevin/VAMP family of synaptic vesicle proteins function on the late secretory pathway in S. cerevisiae. Cell 74(5): 855-861.

Pryor, P.R., Mullock, B.M., Bright, N.A., Lindsay, M.R., Gray, S.R., Richardson, S.C., Stewart, A., James, D.E., Piper, R.C., and Luzio, J.P. 2004. Combinatorial SNARE complexes with VAMP7 or VAMP8 define different late endocytic fusion events. EMBO Rep. 5(6): 590-595.

Quinones, B., Riento, K., Olkkonen, V.M., Hardy, S., and Bennett, M.K. 1999. Syntaxin 2 splice variants exhibit differential expression patterns, biochemical properties and subcellular localizations. J.Cell Sci. 112 ( Pt 23): 4291-4304.

Rothman, J.E., and Warren, G. 1994. Implications of the SNARE hypothesis for intracellular membrane topology and dynamics. Curr.Biol. 4(3): 220-233.

Scherer, W.F., Syverton, J.T., and Gey, G.O. 1953. Studies on the propagation in vitro of poliomyelitis viruses. IV. Viral multiplication in a stable strain of human malignant epithelial cells (strain HeLa) derived from an epidermoid carcinoma of the cervix. The Journal of experimental medicine 97(5): 695-710.

Schiavo, G., Benfenati, F., Poulain, B., Rossetto, O., Polverino de, L.P., Dasgupta, B.R., and Montecucco, C. 1992. Tetanus and botulinum-B neurotoxins block neurotransmitter release by proteolytic cleavage of synaptobrevin. Nature 359(6398): 832-835.

Schiavo, G., Malizio, C., Trimble, W.S., Polverino de Laureto, P., Milan, G., Sugiyama, H., Johnson, E.A., and Montecucco, C. 1994. Botulinum G neurotoxin cleaves VAMP/synaptobrevin at a single Ala-Ala peptide bond. The Journal of biological chemistry 269(32): 20213-20216.

Schiavo, G., Rossetto, O., Catsicas, S., Polverino de, L.P., Dasgupta, B.R., Benfenati, F., and Montecucco, C. 1993. Identification of the nerve terminal targets of botulinum neurotoxin serotypes A, D, and E. J.Biol.Chem. 268(32): 23784-23787.

Sokolov, B.P., Tcherepanov, A.A., Haroutunian, V., and Davis, K.L. 2000. Levels of mRNAs encoding synaptic vesicle and synaptic plasma membrane proteins in the temporal cortex of elderly schizophrenic patients. Biol.Psychiatry 48(3): 184-196.

Sollner, T., Bennett, M.K., Whiteheart, S.W., Scheller, R.H., and Rothman, J.E. 1993. A protein assembly-disassembly pathway in vitro that may correspond to sequential steps of synaptic vesicle docking, activation, and fusion. Cell 75(3): 409-418.

Subramani, S. 1998. Components involved in peroxisome import, biogenesis, proliferation, turnover, and movement. Physiol Rev. 78(1): 171-188.

Sudhof, T.C., Baumert, M., Perin, M.S., and Jahn, R. 1989. A synaptic vesicle membrane protein is conserved from mammals to Drosophila. Neuron 2(5): 14751481.

Sze, C.I., Bi, H., Kleinschmidt-DeMasters, B.K., Filley, C.M., and Martin, L.J. 2000. Selective regional loss of exocytotic presynaptic vesicle proteins in Alzheimer's disease brains. J.Neurol.Sci. 175(2): 81-90. 
Towbin, H., Staehelin, T., and Gordon, J. 1979. Electrophoretic transfer of proteins from polyacrylamide gels to nitrocellulose sheets: procedure and some applications. Proc.Natl.Acad.Sci.U.S.A 76(9): 4350-4354.

Trimble, W.S., Cowan, D.M., and Scheller, R.H. 1988. VAMP-1: a synaptic vesicleassociated integral membrane protein. Proc.Natl.Acad.Sci.U.S.A 85(12): 4538-4542.

Trimble, W.S., Gray, T.S., Elferink, L.A., Wilson, M.C., and Scheller, R.H. 1990. Distinct patterns of expression of two VAMP genes within the rat brain. J.Neurosci. 10(4): 1380-1387.

Yamasaki, S., Baumeister, A., Binz, T., Blasi, J., Link, E., Cornille, F., Roques, B., Fykse, E.M., Sudhof, T.C., Jahn, R., and et al. 1994. Cleavage of members of the synaptobrevin/VAMP family by types $D$ and $F$ botulinal neurotoxins and tetanus toxin. The Journal of biological chemistry 269(17): 12764-12772. 


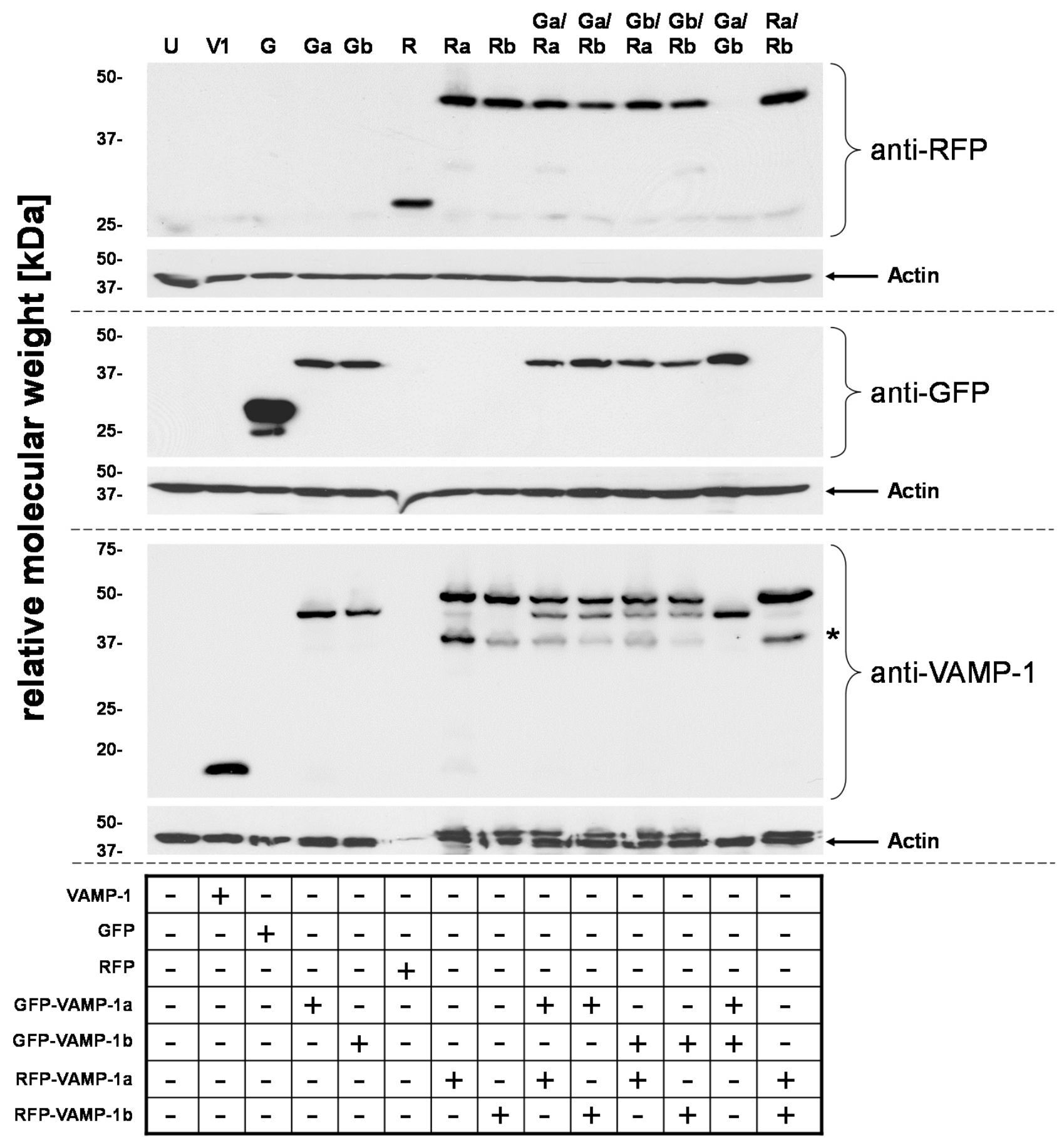

B
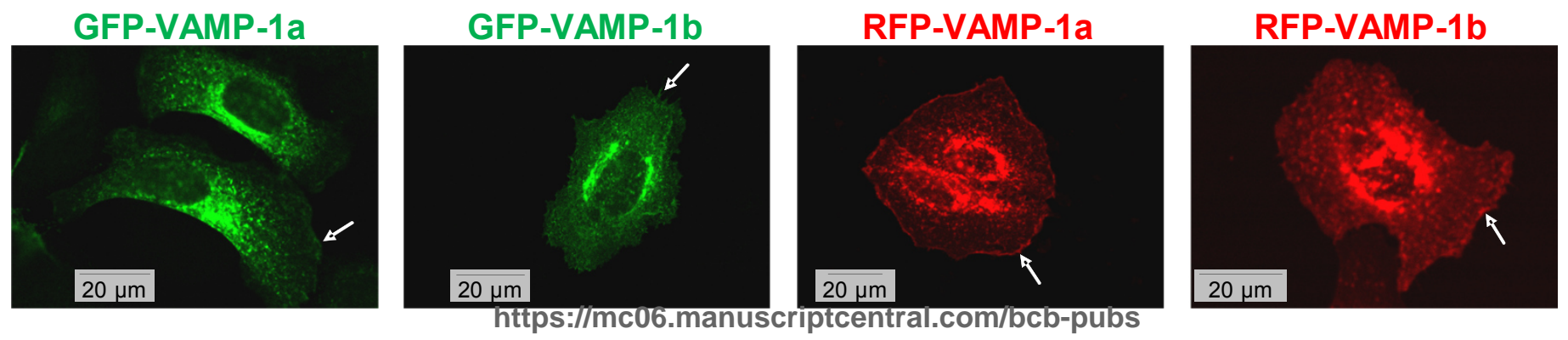


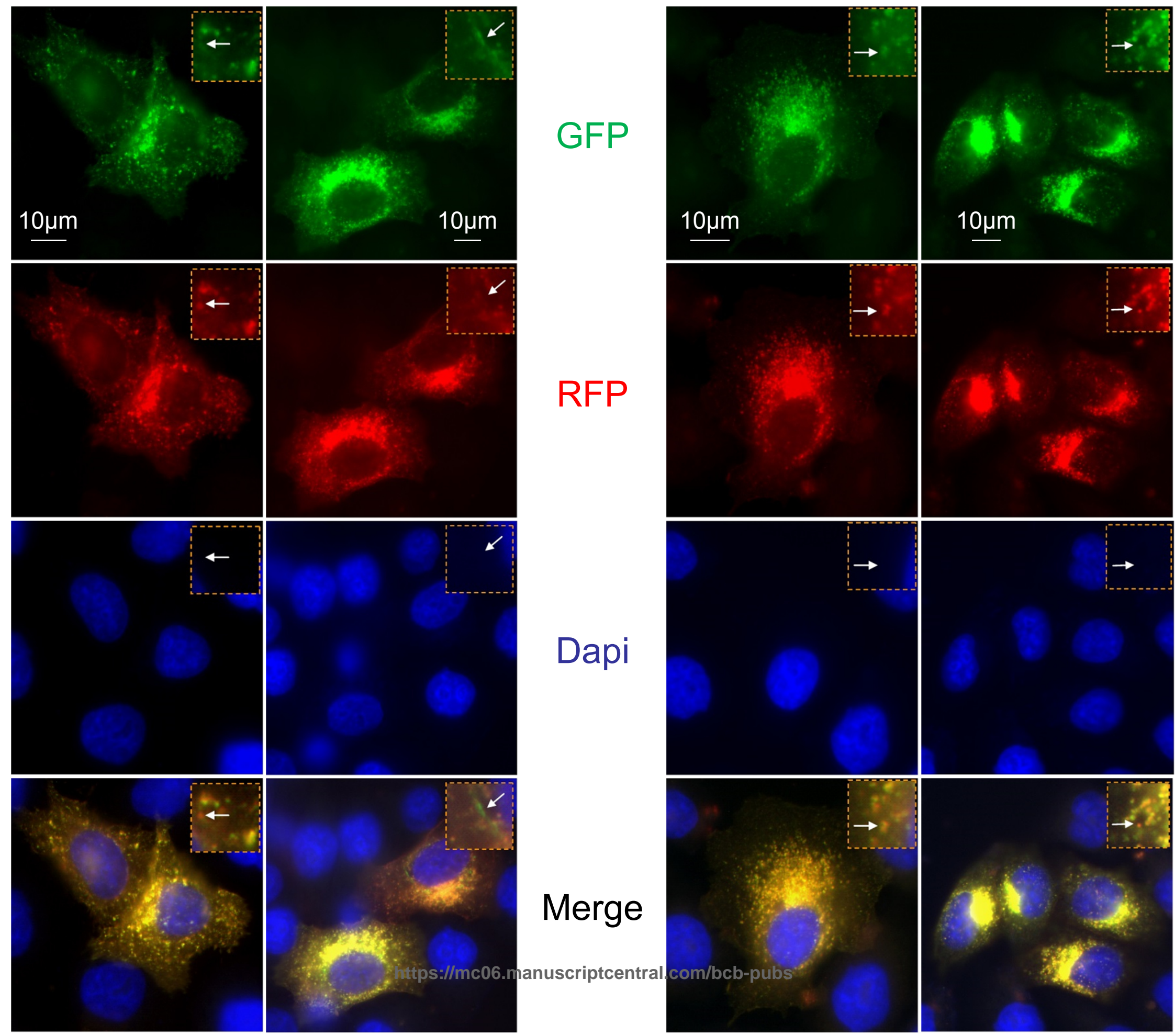


A

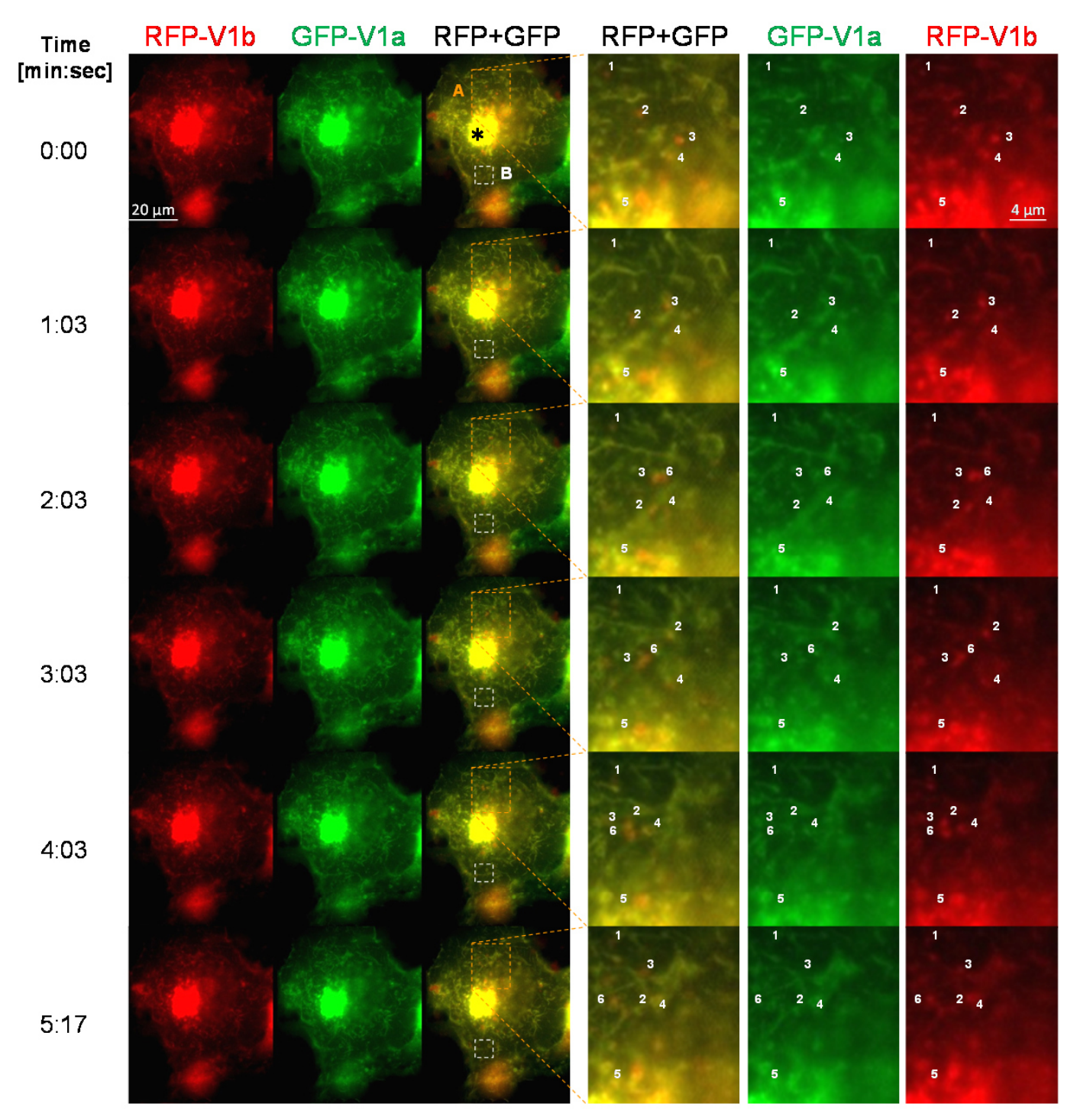

B

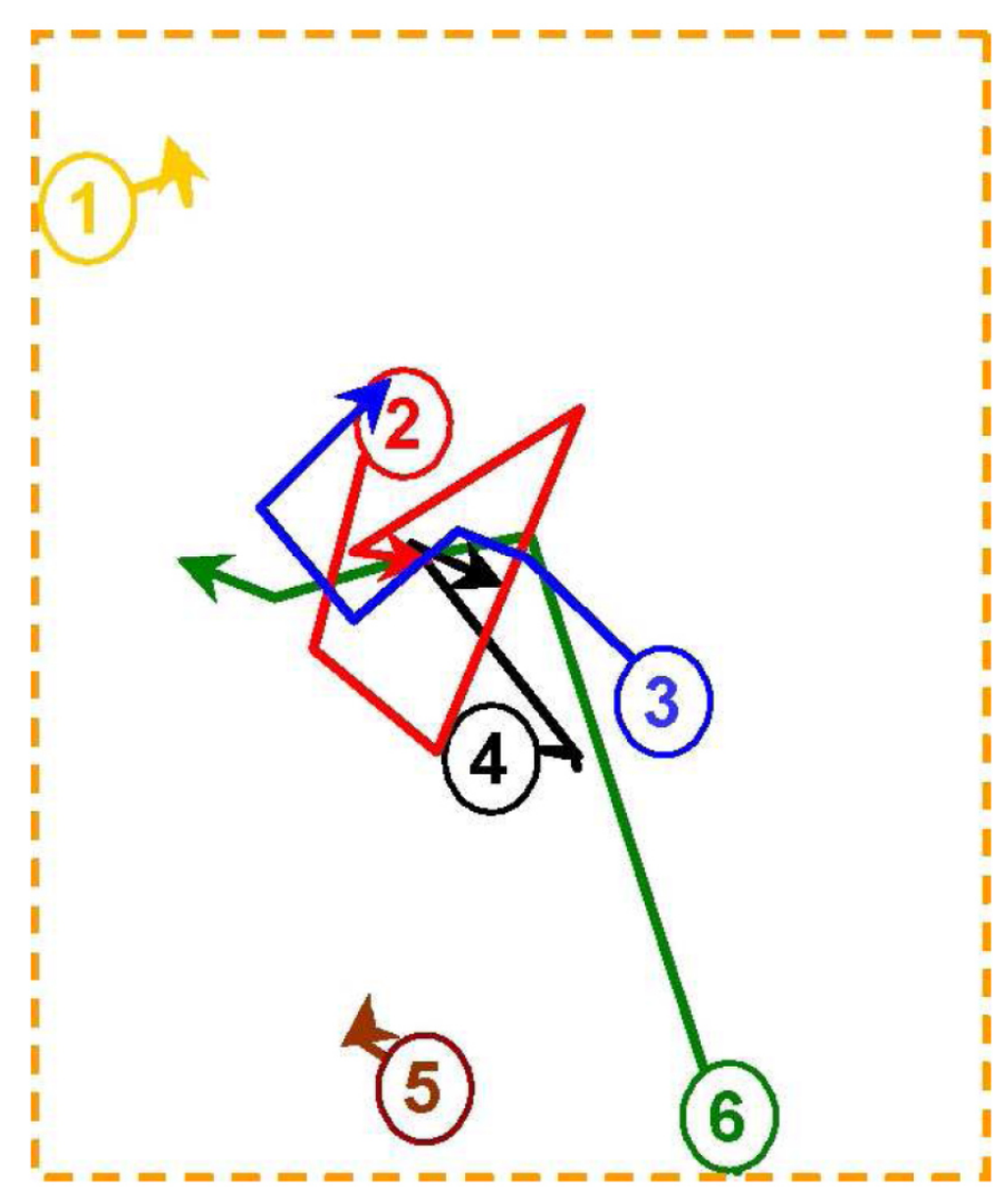

Fig. 3 
A

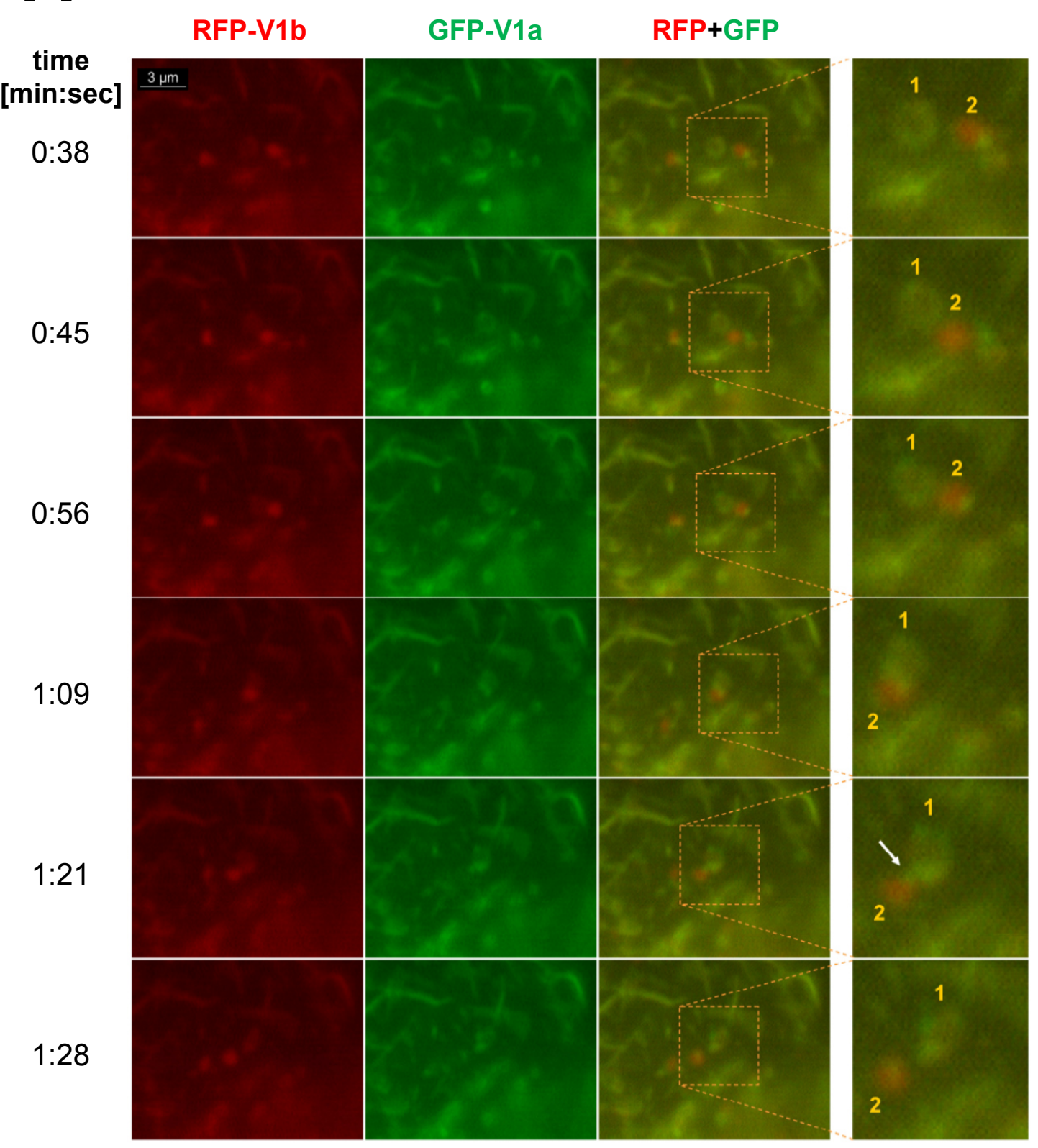

B

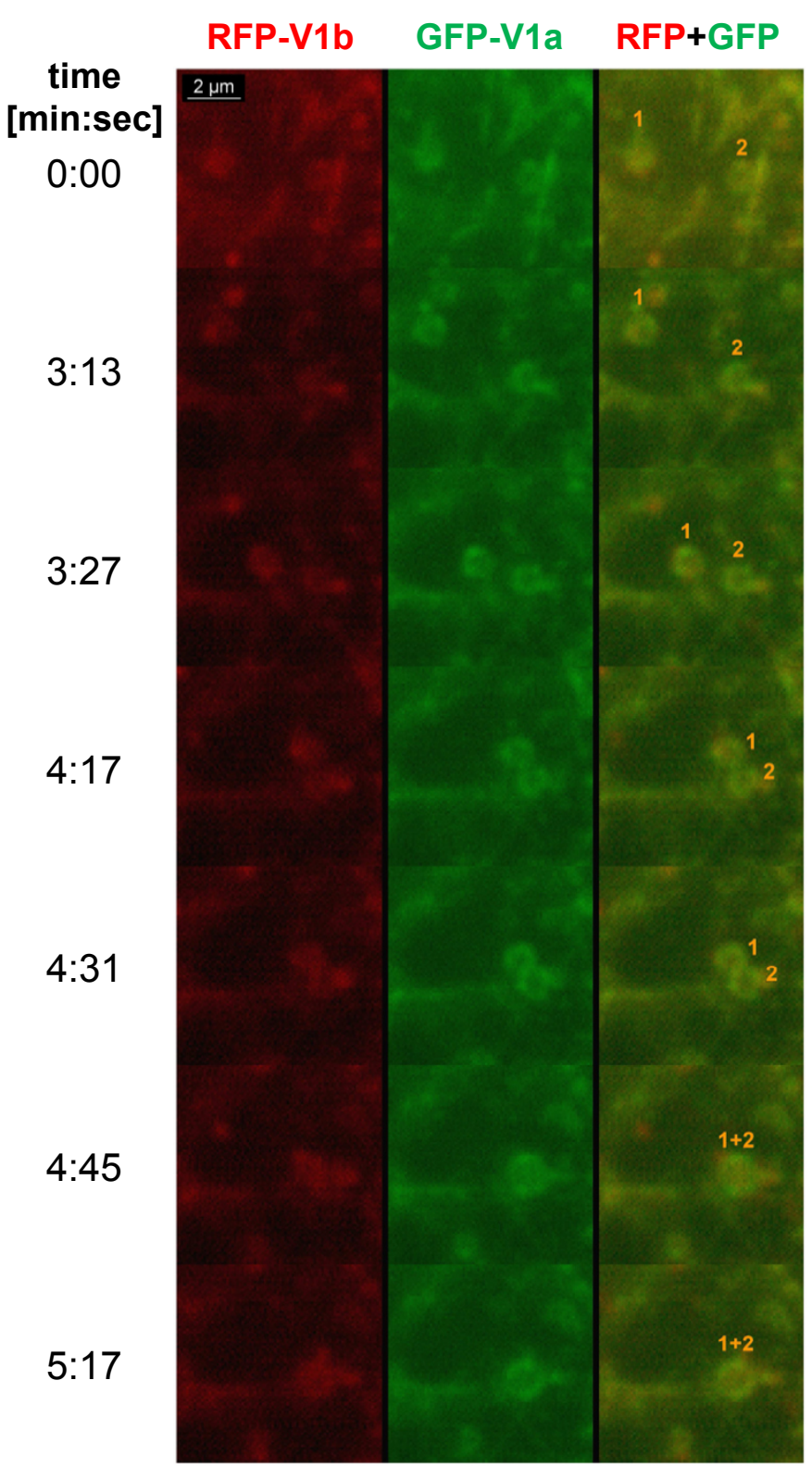


A

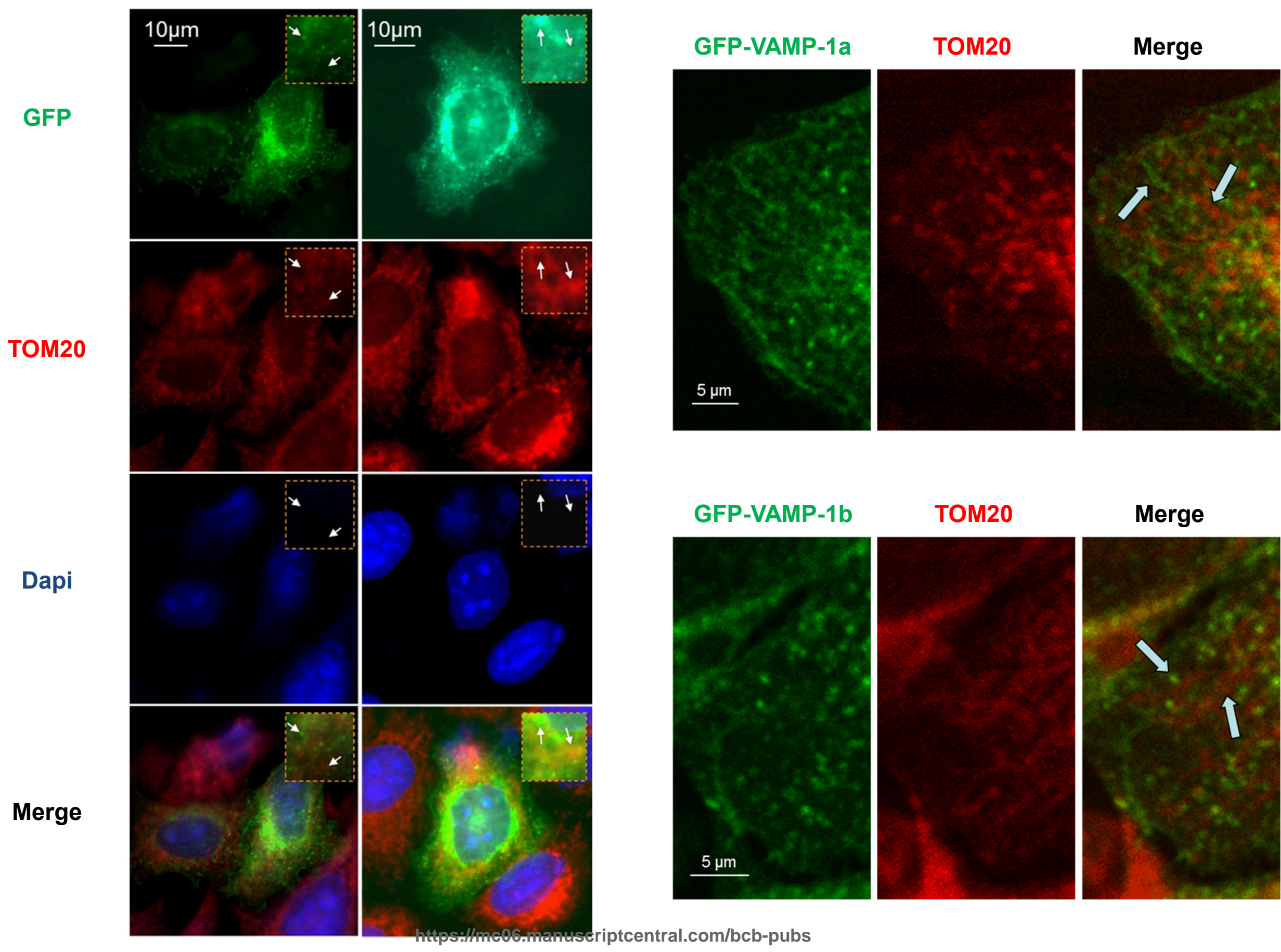




\section{GFP-SKL}

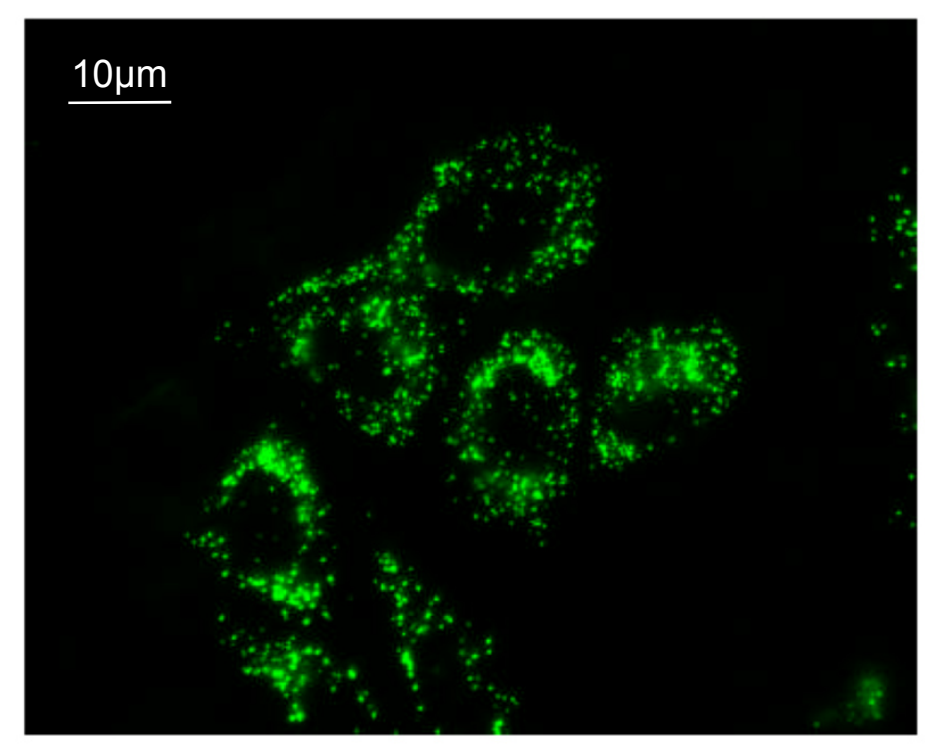

B

$$
10 \mu \mathrm{m}
$$

$t 1$

GFP

\section{GFP-SKYR}

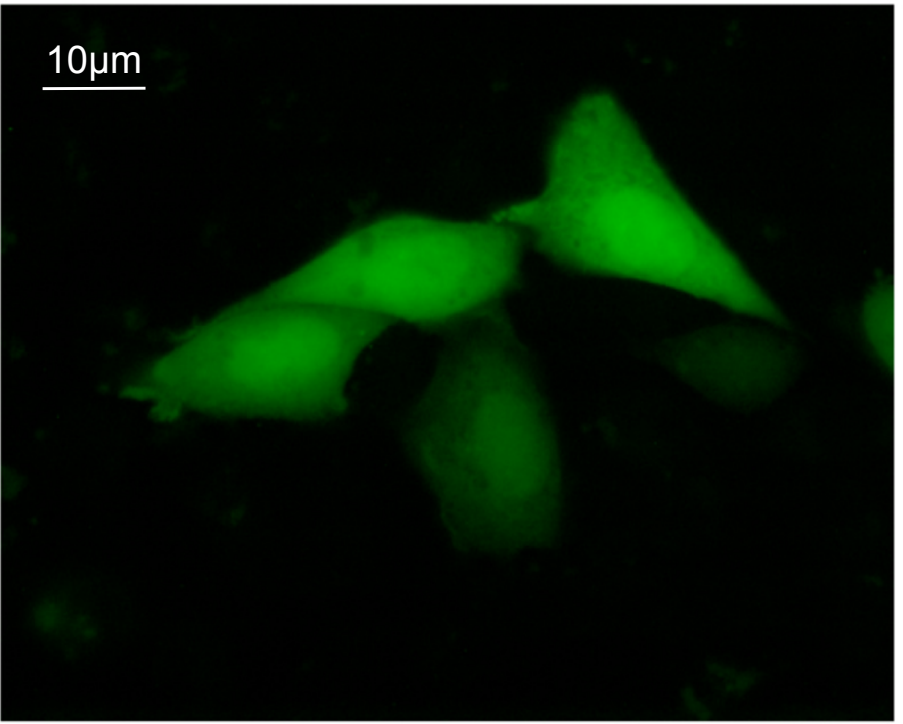

RFP
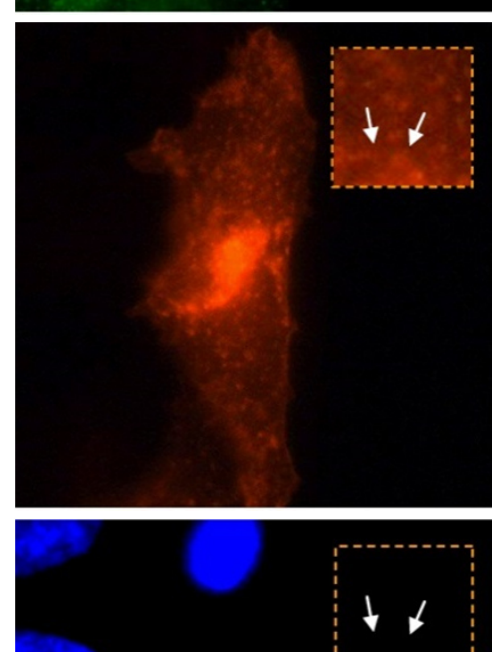

Dapi

Merge

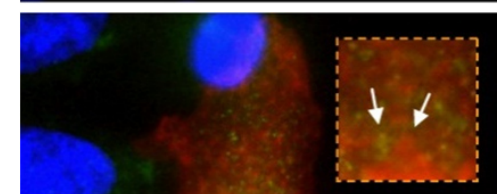

GFP-SKL/RFP-V1b

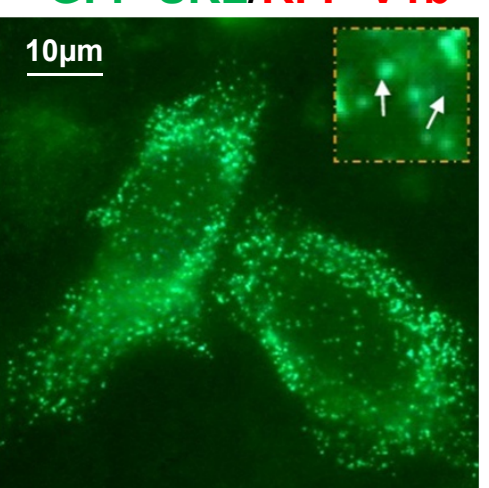

$\uparrow \uparrow$

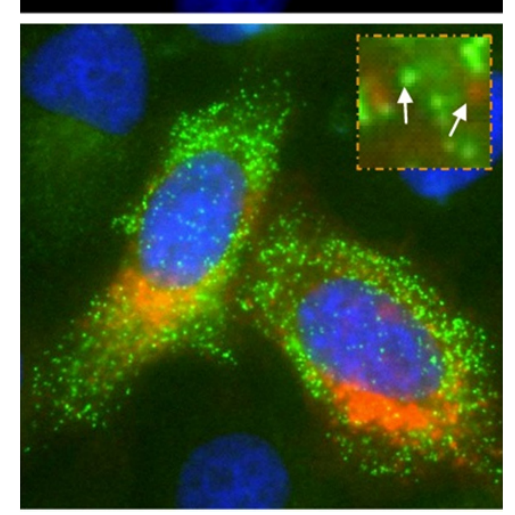

